\title{
Tumor de células gigantes do sacro inoperável: opções terapêuticas e controle da dor*
}

\section{Inoperable Giant Cell Tumor of the Sacrum: Therapeutic Options and Pain Control}

\author{
Eneida de Mattos Brito Oliveira Viana ${ }^{1} \quad$ Katia Torres Batista ${ }^{1} \quad$ José Leite Carneiro Junior ${ }^{1}$ \\ ${ }^{1}$ Rede Sarah de Hospitais de Reabilitação, Brasília, DF, Brasil \\ Address for correspondence Katia Torres Batista, Rede Sarah de \\ Hospitais de Reabilitação, SMHS Qd 301 Bloco A, Brasília, DF, CEP: \\ Rev Bras Ortop 2019;54:347-352. \\ 70335-901, Brasil (e-mail: katiatb@terra.com.br; 203911@sarah.br).
}

\section{Resumo \\ Palavras-chave \\ - tumores de células gigantes \\ - ortopedia \\ - dor crônica}

O tumor de células gigantes (TCG) do sacro é raro e seu tratamento é complexo, devido à dificuldade para a exerese cirúrgica e a baixa resposta às outras opções terapêuticas. Entre os desafios relacionados a este tumor está o controle do seu crescimento e da dor. No presente trabalho, relatamos um caso de tumor de células gigantes do sacro inoperável, apresentando as opções terapêuticas de embolização e de radioterapia para o controle da dor. Relato do caso: paciente do sexo masculino, admitido aos 39 anos de idade, apresentando dor na região sacral com irradiação para os membros inferiores (MMII), com diagnóstico de TCG do sacro inoperável. Realizou-se embolização, uso de interferon, radioterapia, tratamento da dor com opioides e medicamentos adjuvantes, associados a programa de reabilitação. Descreveu-se o difícil controle do crescimento tumoral e da dor ao longo do seguimento, com desfecho estável após 9 anos.

Sacral giant cell tumor is rare and its treatment is complex, due to the difficulty for surgical exeresis and to the low response to other therapeutic options. Among the challenges related to this tumor are the control of its growth and pain. In the present work, we report a case of an inoperable giant cell tumor of the sacrum presenting the therapeutic options of embolization and radiotherapy for pain control. We report the case of a male patient, 39 years old, presenting with pain in the sacral region with irradiation to the lower limbs, with an inoperable sacral giant cell tumor. Embolization, radiotherapy, pain management with opioids, others drugs, and a rehabilitation program were performed. We describe the difficult control of the growth of the tumor and of the pain during the follow-up, with a stable outcome after 9 years.

- chronic pain

\section{Introdução}

Trabalho desenvolvido na Rede Sarah de Hospitais de Reabilitação, Brasília, DF, Brasil, e apresentando no Instituto de ensino e pesquisa do Hospital Sírio-Libanês para obtenção de título de especialista em cuidados do paciente com dor.

(1) Katia Torres Batista's ORCID is https://orcid.org/0000-0003-13004281.

received

January 4, 2018

accepted

May 7, 2018
DOI https://doi.org/

10.1055/s-0039-1692450.

ISSN 0102-3616.
Os tumores de células gigantes (TCGs) são raros, constituem entre 8 e 10\% dos tumores ósseos primários benignos, têm maior prevalência após a maturidade esquelética ( $3^{\text {a }}$ e $4^{\text {a }}$ décadas de vida) e pequena predileção em mulheres. Eles acometem preferencialmente ossos longos e, menos
Copyright $\odot 2019$ by Sociedade Brasileira License terms de Ortopedia e Traumatologia. Published by Thieme Revnter Publicações Ltda, Rio de Janeiro, Brazil 
frequentemente, vértebras, a pelve e o sacro. Podem estar associados a condições pseudotumorais, a malignidade, a metástases (10\%), principalmente para o pulmão, e a recidiva local. O principal sintoma é a dor $(54,4 \%){ }^{1-3}$

O tratamento dos TCGs é cirúrgico, pela excisão tumoral completa e pelo preenchimento do defeito com enxerto ósseo, polimetilmetacrilato ou endoprótese, sendo raramente indicada a amputação, por ser um tumor benigno. ${ }^{1}$ O maior desafio reside nos casos localizados na coluna dorsal e no sacro, com destruição extensa e opções cirúrgicas restritas. Nos TCGs sacrais, a curetagem com cimentação é a melhor opção. A sacrectomia piora a qualidade de vida por incontinência esfincteriana e anestesia da região perineal. ${ }^{1}$

Os estudos radiográficos demonstram lesão lítica, solitária, insuflativa, excêntrica, com afinamento ou erosão da cortical. $^{2}$ Dor e aumento de volume local são as queixas mais frequentes por infiltração óssea local e à distância. Os opioides são os fármacos mais efetivos usados para dor moderada e intensa, porém o seu uso em casos complexos exigem o manejo na dose, na forma de administração e a associação de outros tratamentos. ${ }^{4}$

Descrever as opções terapêuticas e do controle da dor em caso complexo de TCG sacral inoperável.
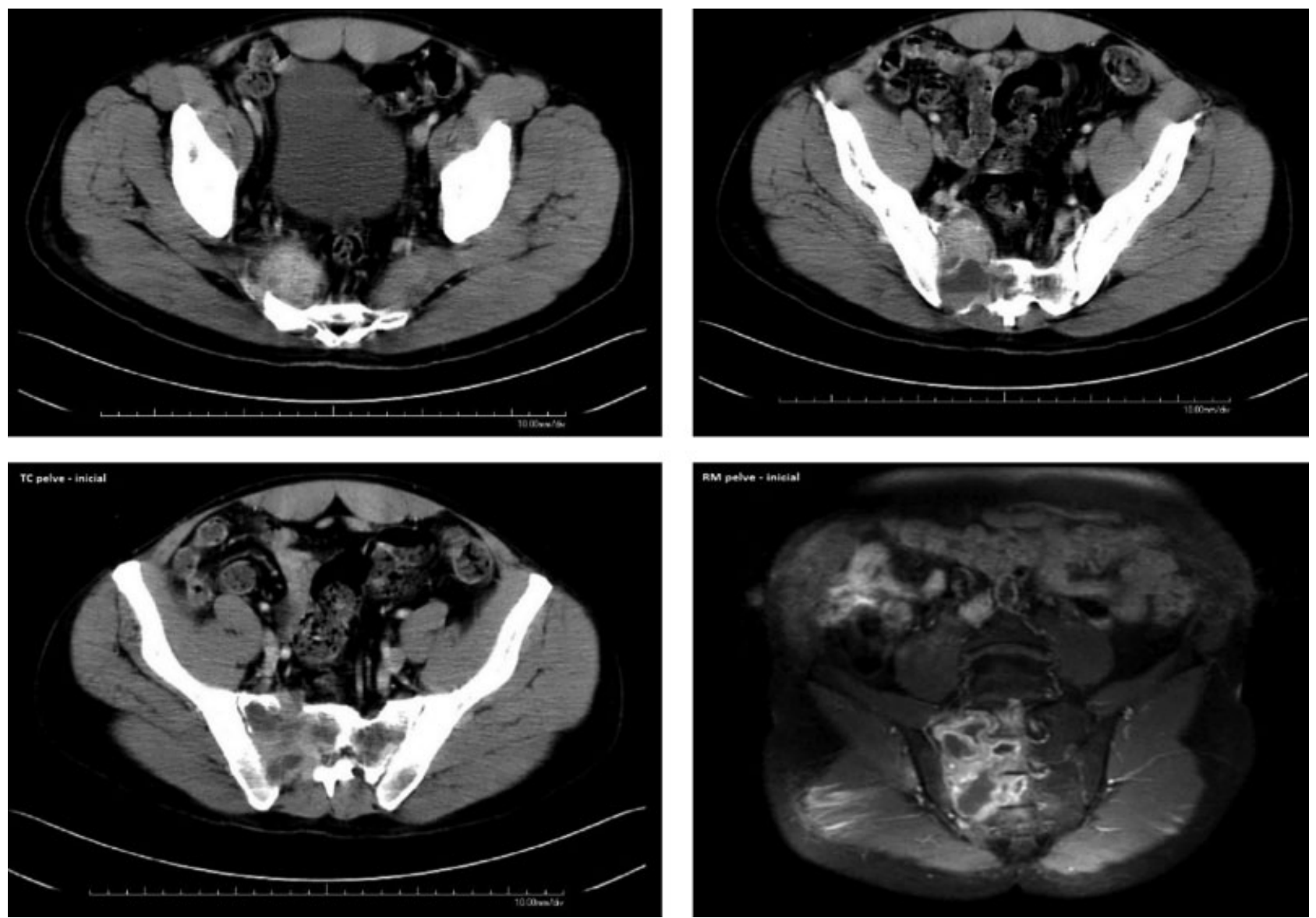

Fig. 1 Exame de ressonância magnética nuclear com lesão osteolítica $(8,3 \times 5,8 \times 4,8 \mathrm{~cm})$ com áreas de ruptura cortical e componente extraósseo, central e lateral direita do sacro (S1 a S4), forames sacrais, canal raquiano sacral, articulação sacroilíaca; pequeno comprometimento cortical do ilíaco direito. O centro de aspecto cístico com níveis líquidos. Envolvimento das raízes sacrais e aparente infiltração do músculo piriforme, com edema dos músculos glúteos médio e máximo. Íntimo contato com o nervo ciático, com os vasos ilíacos, glúteos superiores e inferiores; espondilólise bilateral de L4 associada a uma anterolistese de L4 sobre L5 grau 2, determinando estenose dos forames neurais nesse nível. 

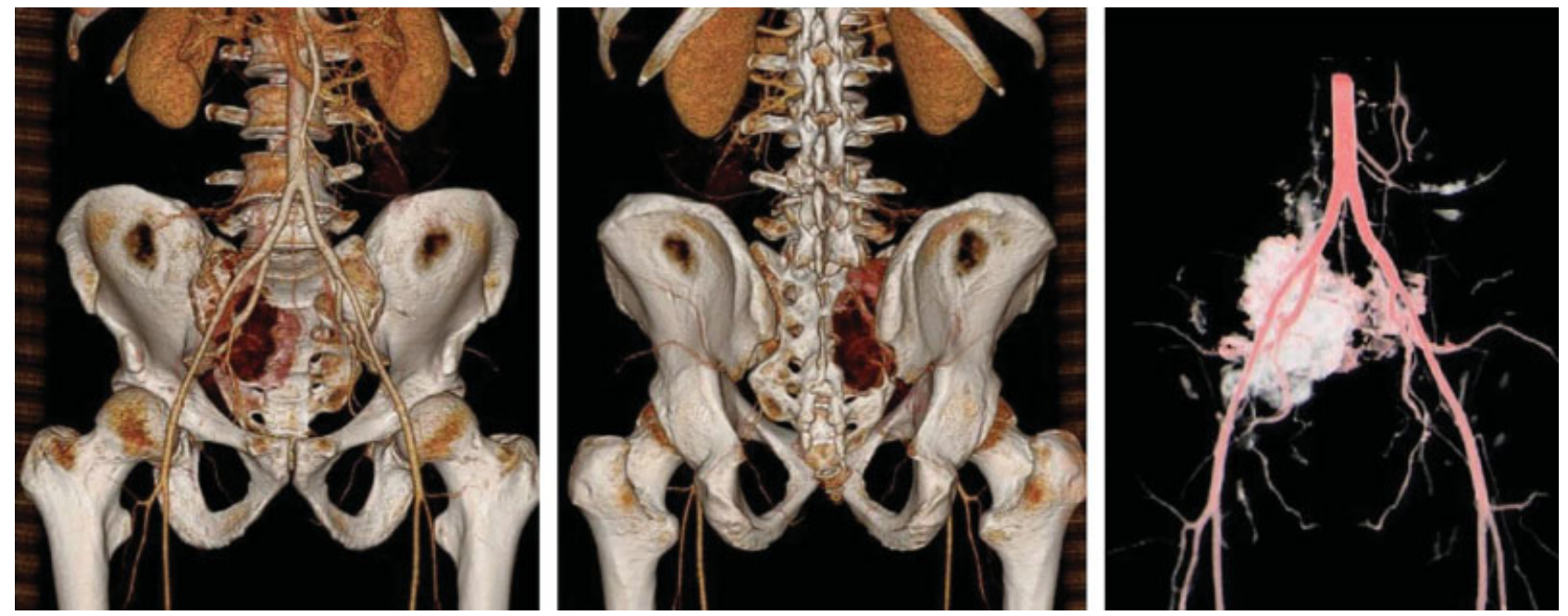

Fig. 2 Embolização tumoral com gelfoam e embosferas através de cateterização seletiva das artérias sacral média, radicular de L5, glútea superior e ilíaca interna à direita, e irrigação pela artéria sacral lateral esquerda.

após as quais houve intensificação da dor. O controle da dor foi inicialmente tentado com os opioides morfina (doses de $5 \mathrm{mg}$ a $200 \mathrm{mg}$ de $4 \mathrm{em} 4$ horas), fentanil e metadona, associados à gabapentina, para controle da dor neuropática, e antidepressivos tricíclicos (amitriptilina), anti-inflamatórios e analgésicos. Foi utilizado o interferon alfa $2 \mathrm{~A}(1,1 \mu \mathrm{U} /$ $\mathrm{m}^{2}$, aumentando-se até $4,4 \mu \mathrm{U} / \mathrm{m}^{2}$ ) como terapia antiangiogênica por 7 meses. Com a piora da dor à deambulação, instalou-se cateter intratecal em L3/L4 e bomba de infusão de fentanil. Apesar da melhora da dor, o cateter apresentava escapes frequentes, devido a espondilólise com listese grau I L4-L5 e redução do forame neural evidenciado por hipoestesia em L5-S1, reflexos patelar e aquileu abolidos, Laségue positivo e perda total de movimentos do tornozelo à direita. A eletroneuromiografia evidenciou lesão do nervo ciático direito. A tomografia da pelve e da coluna lombossacra constatou crescimento tumoral e envolvimento das estruturas nervosas adjacentes.

$\mathrm{O}$ paciente foi submetido a 2 bloqueios radiculares em L4/L5 (-Fig. 3) com bupivacaína e metilprednisolona. Devido à falha no tratamento com interferon e à persistência do quadro de dor, o paciente foi encaminhado no $11^{\circ}$ mês à radioterapia na dose de $4.500 \mathrm{cGy}$, evoluindo com controle parcial da dor e tumoral. Do $11^{\circ}$ mês até o $28^{\circ}$ mês, o paciente estava dependente para as atividades de vida diária (AVD), tinha controle esfincteriano, porém com disfunção erétil e disautonomia, controlado com inibidores da fosfodiesterase. Encaminhado à hidroterapia e fisioterapia, apresentou melhora da dor e do humor. A tomografia de controle apresentava mínima redução da lesão sacral.

No $29^{\circ}$ mês, sem fatores desencadeantes, a dor voltou, e os medicamentos foram reajustados, conforme demonstrado na -Tabela 1, obtendo-se controle álgico. No $35^{\circ}$ mês, o paciente deambulava sem auxílio e apresentava hipoestesia tátil e dolorosa, pé caído (prescrito órtese tornozelo-pé). Mantido seguimento anual com redução progressiva e ajustes da medicação analgésica e retirada da bomba de analgesia controlada pelo paciente (PCA) no $91^{\circ}$ mês. No $9^{\circ}$ ano $\left(96^{\circ}\right.$ mês), o paciente mantinha um volumoso tumor sacral estável (-Fig. 4), sem tratamento oncológico específico, sem dor e sem qualquer medicação analgésica, e retornou às suas AVDs e ao trabalho.

$\mathrm{O}$ projeto da presente pesquisa foi avaliado e aprovado pelo Comitê de ética em pesquisa/Associação das Pioneiras Sociais (CEP/APS).

\section{Discussão}

O TCG, embora seja um tumor benigno, pode ter comportamento agressivo e ser inoperável. O maior desafio, como demonstrado no presente relato de caso, reside nos casos localizados no sacro quando há destruição extensa, as opções cirúrgicas são restritas, associado ao cisto aneurismático, visto pelo aumento progressivo da lesão e a compressão das raízes e da medula, causando sintomas de dor, fraqueza e distúrbios sensitivos nos membros. O cisto aneurismático descrito no exame histopatológico e de imagem do presente caso poderia ser considerado como fenômeno associado ao TCG, não diferenciando o tratamento cirúrgico, que incluiria, se possível, a ressecção marginal em monobloco. Todavia, segundo a experiência em nosso serviço, e de outros autores, o tratamento cirúrgico por excisão com margem ampla ou limite que envolve os segmentos sacrais superiores e a linha média envolveria a sacrectomia total, que além dos riscos de hemorragia maciça, de infecção e de déficit neurológico, cursaria com distúrbios de esfíncter, instabilidade pélvica e espinhal, risco de recorrência local e a piora importante da qualidade de vida. ${ }^{1}$ A embolização foi indicada no presente caso como tentativa de redução tumoral e da dor, e está descrita somente para os tumores inoperáveis. No presente caso, foram realizadas duas embolizações sem redução tumoral e com exacerbação da dor, mantendo as condições de inoperabilidade. Os resultados poderiam ser eficazes, mas temporários, inclusive para dor, devido à recanalização dos vasos e ao crescimento tumoral. ${ }^{2,3}$ 


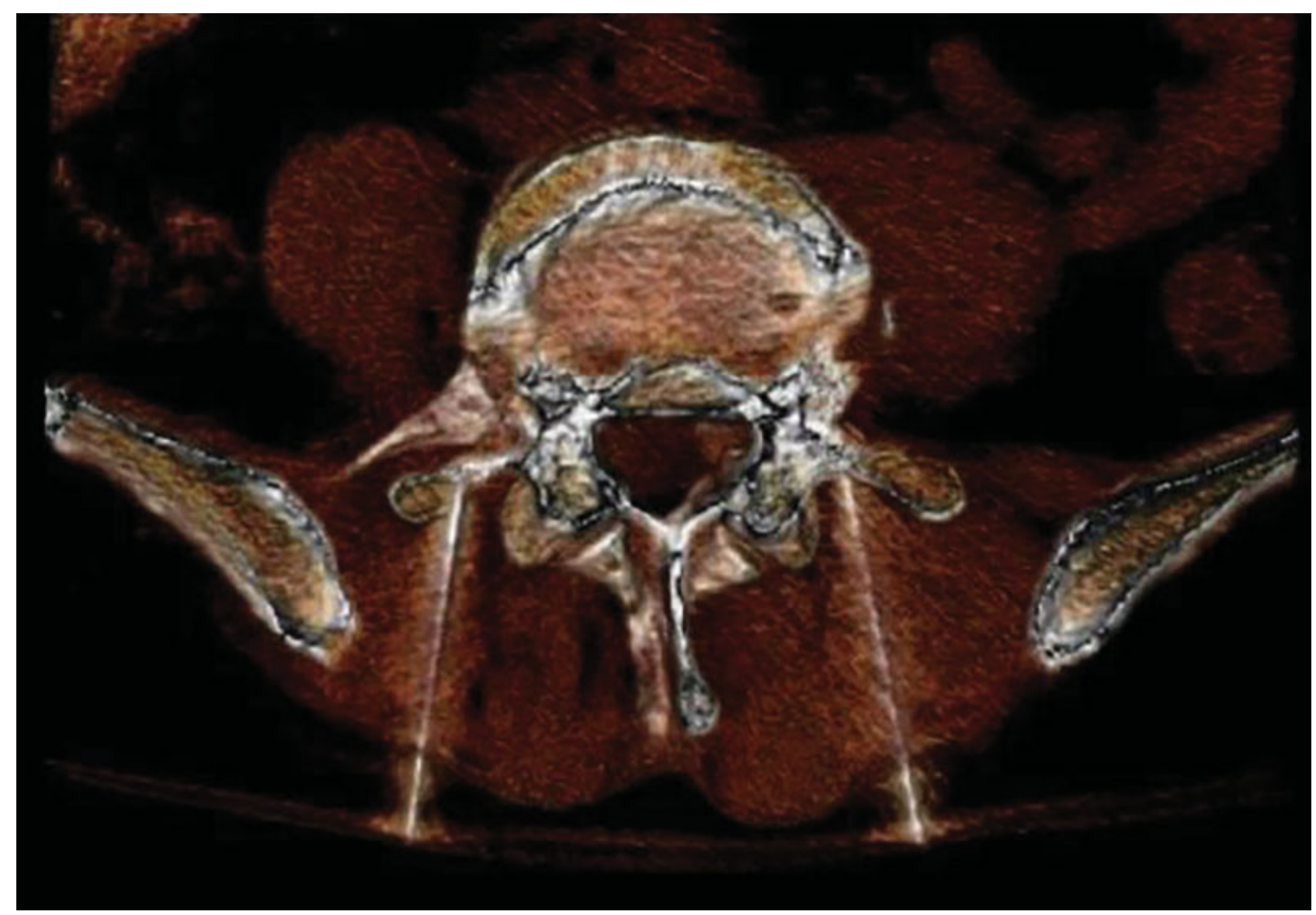

Fig. 3 Bloqueio perirradicular bilateral em L4/L5, com bupivacaína e metilprednisolona. Escore de dor pré-bloqueio = 8; e após = 0/10.

A quimioterapia como opção terapêutica foi abandonada devido ao comportamento benigno tumoral e aos efeitos colaterais. Tendo em vista a pouca resposta e a piora da dor à embolização realizada, optou-se pela terapia com interferon alfa $2 \mathrm{~A}$, anticorpo que bloqueia a ação dos osteoclastos, o qual têm se mostrado eficiente na redução desses tumores por certo tempo, mas que não foi eficaz no presente caso após 7 meses de uso. ${ }^{5}$ Outra opção de tratamento descrita nos tumores ósseos irressecáveis é a radioterapia. A radioterapia na dose de $4.500 \mathrm{cGy}$ no leito tumoral foi indicada e evidenciou discreta redução do tumor. Entretanto, ela tem aplicação duvidosa nos TCGs, por serem estes neoplasias benignas com poucas atipias celulares e pelo risco de degeneração sarcomatosa, sendo indicada para lesões avançadas, com maciça destruição óssea, múltiplas recorrências, infecções secundárias, degenerações malignas na coluna vertebral ou no sacro, e por isso foi aplicada neste caso de difícil controle. $^{6}$

Opioides, analgésicos, anestésicos e corticosteroides foram usados para o controle da dor por infiltração óssea, em dose de manutenção ou em bolus nas exacerbações, utilizados neste caso desde a admissão até o $91^{\circ}$ mês, ajustando-se as doses conforme os episódios de crise associados a analgésicos (paracetamol, acetaminofeno), antiinflamatórios (tenoxicam, naproxeno), antidepressivos tricíclicos, anticonvulsivantes, relaxantes musculares e medi- camentos para controle de efeitos colaterais. Outras opções, embora não utilizadas no presente caso, seriam os bisfosfonatos, eficazes na diminuição da hipercalcemia tumoral, com efeito analgésico sobre a dor óssea secundária à remodelação, e o denosumabe, ${ }^{7}$ medicamento composto de proteína de anticorpo monoclonal, que interfere na ação de outra proteína envolvida no processo de ativação da degradação óssea, que determina a redução do número e da função dos osteoclastos (células presentes nos ossos e responsáveis pela degradação do tecido ósseo), resultando na redução da reabsorção e da destruição ósseas, comumente induzidas pelo câncer, é indicado para o tratamento de altos níveis sanguíneos de cálcio causados por câncer, após a falha no tratamento com bisfosfonato. Na época deste estudo o seu uso era limitado pelo custo elevado e outros fatores.

Vale destacar que, no Brasil, estima-se que de 62 a $90 \%$ dos pacientes com neoplasias ósseas cursam com dor, ${ }^{8}$ Entre as possíveis causas estão aquelas devido a invasão óssea (46\% a 92\%), visceral, do sistema nervoso, de partes moles, aumento da pressão intracraniana (12\% a $29 \%$ ), espasmo muscular, linfedema, lesões de decúbito, constipação intestinal, e relacionadas ao tratamento cirúrgico (5\% a 20\%) (dor aguda, pós-amputação, dor fantasma); por quimioterápicos (mucosite, neuropatia periférica, neuralgia pós-herpética, espasmos vesicais, necrose da cabeça do 
Tabela 1 Evolução mensal do tratamento e intercorrências

\begin{tabular}{|c|c|c|}
\hline Mês & Intercorrência & Tratamento \\
\hline $\begin{array}{l}1^{\circ} \text { Admissão } \\
\text { Embolização intra-arterial no território } \\
\text { tumoral irrigado pela artéria sacral } \\
\text { lateral esquerda }\end{array}$ & $\begin{array}{l}\text { Dor } \\
\text { Intensificação do quadro álgico, } \\
\text { (Escore 10/10) }\end{array}$ & $\begin{array}{l}\text { Morfina } 10 \mathrm{mg} 6 / 6 \text { horas, amitriptilina } \\
50 \text { mg/dia. } \\
\text { Substituição por fentanil transdérmico } \\
\text { (200 mcg) e gabapentina ( } 1.200 \mathrm{mg} / \mathrm{dia})\end{array}$ \\
\hline $\begin{array}{l}3^{\circ} \text { Volume tumoral inalterado } \\
\text { Embolização tumoral } \\
\text { Interferon alfa } 2 \mathrm{~A}\left(1,1 \mu \mathrm{U} / \mathrm{m}^{2}\right)\end{array}$ & Reagudização da dor & $\begin{array}{l}\text { Gabapentina } 600 \mathrm{mg} 8 / 8 \text { horas } \\
\text { fentanil transdérmico }(200 \mathrm{mcg}) \text {, } \\
\text { tenoxicam } 20 \mathrm{mg} / \mathrm{dia} \\
\text { paracetamol } 750 \mathrm{mg} 6 / 6 \text { horas. } \\
\text { Amitriptilina } 75 \mathrm{mg} / \text { dia }\end{array}$ \\
\hline $4^{\circ}$ & $\begin{array}{l}\text { Dor à deambulação. Dificuldade de } \\
\text { aderência do adesivo devido a sudor- } \\
\text { ese profusa. }\end{array}$ & $\begin{array}{l}\text { Instalação de cateter intratecal com bomba } \\
\text { de PCA com fentanil ( } 5 \text { mcg; intervalo de } \\
\text { bloqueio: } 30 \text { minutos; infusão } \\
\text { contínua: } 0,5 \text { mcg/h; total contínuo: } \\
12 \text { mcg/dia) }\end{array}$ \\
\hline $5^{\circ}$ Interferon alfa $2 \mathrm{~A}\left(2,2 \mu \mathrm{U} / \mathrm{m}^{2}\right)$ & $\begin{array}{l}\text { Síndrome de abstinência ao Fentanil } \\
\text { Dor em pontadas em todo membro } \\
\text { inferior direito, devido à presença de } \\
\text { espondilólise de L4 com listese grau I } \\
\text { L4-L5 e redução do forame neural. }\end{array}$ & $\begin{array}{l}\text { Instalação de bomba intratecal Synchromed } \\
\text { II, em altura aproximada de L3/L4. Iniciada } \\
\text { infusão de fentanil com dose contínua diária } \\
\text { de } 10 \mathrm{mcg} / \text { dia. } \\
\text { Feito ajustes progressivos do Fentanil } \\
\text { intratecal que, posteriormente, foi trocado } \\
\text { por morfina. } \\
\text { Aumentada infusão intratecal da droga, } \\
\text { associado tramadol e mantida morfina para } \\
\text { resgate. } \\
\text { Bloqueio perirradicular bilateral em L4/L5, } \\
\text { com bupivacaína e metilprednisolona. } \\
\text { Segundo bloqueio perirradicular bilateral } \\
\text { em L4/L5, com bupivacaína e } \\
\text { metilprednisolona. }\end{array}$ \\
\hline $\begin{array}{l}10^{\circ} \text { Crescimento tumoral } \\
\text { Interferon alfa } 2 \mathrm{~A}\left(4,4 \mu \mathrm{U} / \mathrm{m}^{2}\right)\end{array}$ & $\begin{array}{l}\text { Dor intensa e queimação irradiada da } \\
\text { nádega para região posterior de todo } \\
\text { membro inferior direito; sudorese } \\
\text { profusa, emagrecido e gemente e com } \\
\text { lesão por pressão em região cubital } \\
\text { devido ao apoio. }\end{array}$ & $\begin{array}{l}\text { Amitriptilina } 75 \mathrm{mg} / \mathrm{dia} \\
\text { Gabapentina } 2.400 \mathrm{mg} / \text { dia e solução intra- } \\
\text { tecal de morfina } 2,5 \mathrm{mg} / \text { dia, associada a } \\
\text { bupivacaína } 1,25 \mathrm{mg} / \mathrm{dia} \text {. (Escore de } 9 \text { para } \\
\text { 4/10). }\end{array}$ \\
\hline $\begin{array}{l}11^{\circ} \text { Radioterapia - } 4.500 \text { cGy em leito } \\
\text { tumoral }\end{array}$ & $\begin{array}{l}\text { Queimação intensa em região plantar } \\
\text { esquerda, não conseguindo encostar o } \\
\text { pé no chão. O cateter estava no espaço } \\
\text { subaracnóideo. }\end{array}$ & $\begin{array}{l}\text { Clonidina } 42 \text { mcg/dia; solução intratecal de } \\
\text { morfina; } \\
\text { Gabapentina } 2.700 \text { mg/dia. } \\
\text { Troca de cateter; constatado íntegro mas } \\
\text { enrolado sob a bomba. }\end{array}$ \\
\hline $12^{\circ}-14^{\circ}$ Hidroterapia e fisioterapia & $\begin{array}{l}\text { Instável, parcialmente dependente } \\
\text { para todas AVDs }\end{array}$ & $\begin{array}{l}\text { Morfina ( } 3,5 \mathrm{mg} / \mathrm{dia}) \text {, bupivacaina, } \\
\text { amitriptilina } 125 \mathrm{mg} / \mathrm{dia} \text {, gabapentina } \\
2.400 \mathrm{mg} / \mathrm{dia} \text {, tizanidina } 6 \mathrm{mg} / \mathrm{dia}, \\
\text { metadona } 15 \mathrm{mg} / \text { dia e naproxeno } \\
1 \mathrm{~g} / \text { dia. }\end{array}$ \\
\hline $29^{\circ}$ Órtese tornozelo-pé & Recrudescência da dor & $\begin{array}{l}\text { Aumentada morfina intratecal } 2 \mathrm{mg} / \text { dia e } \\
\text { metadona } 5 \mathrm{mg} 12 / 12 \mathrm{~h} \text {, amitriptilina } \\
25 \mathrm{mg} / \text { noite e naproxeno } 250 \mathrm{mg} 12 / 12 \mathrm{~h} \text {. }\end{array}$ \\
\hline $87^{\circ}$ & $\begin{array}{l}\text { Vencimento do tempo útil da bomba } \\
\text { de PCA }\end{array}$ & Troca da bomba de PCA \\
\hline $91^{\circ}$ & Exteriorização da bomba de PCA & $\begin{array}{l}\text { Retirada do sistema de injeção intratecal; } \\
\text { Infusão venosa contínua de morfina } \\
4 \text { mg/hora e metadona } 10 \mathrm{mg} 8 / 8 \text { horas } \\
\text { horas, reduzida para } 5 \mathrm{mg} \text { de } 8 / 8 \text { horas } \\
\text { por } 1 \text { ano; gabapentina } 300 \mathrm{mg} 12 / 12 \text { horas } \\
\text { e amitriptilina } 25 \mathrm{mg} / \text { noite. }\end{array}$ \\
\hline $\begin{array}{l}96^{\circ} \text { Estabilização do crescimento } \\
\text { tumoral }\end{array}$ & & $\begin{array}{l}\text { Sem tratamento oncológico específico, sem } \\
\text { dor e sem qualquer medicação analgésica, } \\
\text { retornou as suas AVDs e ao trabalho. }\end{array}$ \\
\hline
\end{tabular}

Abreviação: PCA, analgesia controlada pelo paciente. 

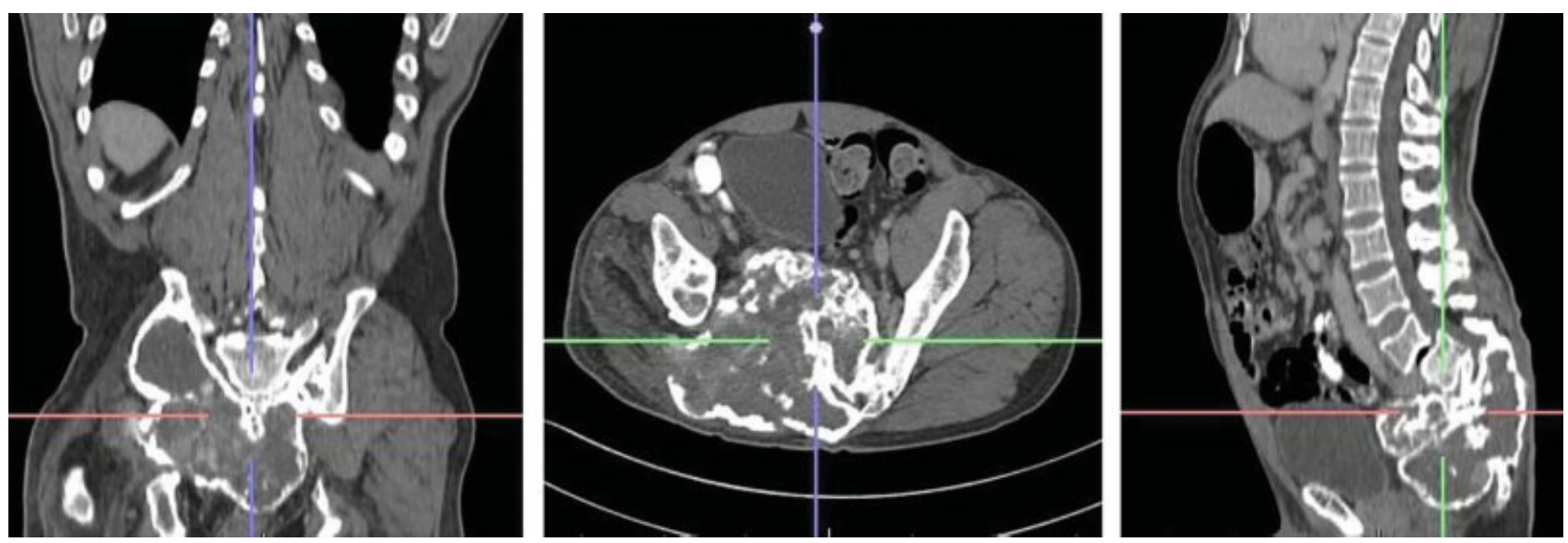

Fig. 4 Exame de ressonância magnética nuclear evidenciando o controle do tumor sacral extenso.

fêmur); radioterápico (mucosite, esofagite, retite actínica, radiodermite, mielopatia e fibrose actínica de plexo) e das condições associadas (8\% a 22\%) (osteoartrite; espondiloartose, fibromialgia, enxaqueca e outros).

No presente relato, observou-se o difícil controle do crescimento tumoral e da dor relacionada. Nos episódios de exacerbação da dor de origem óssea, ocasionada tanto pelo crescimento tumoral, pela invasão óssea, neuropática, quanto pela compressão radicular associada à imobilidade $\mathrm{e}$ espasmos musculares, utilizou-se opioides, analgésicos potentes e medicamentos adjuvantes com doses por via oral e em bomba de PCA intratecal para tratamento e controle da dor. ${ }^{4,8}$ Observou-se também os componentes miofascial, postural, redução da massa muscular e do condicionamento, contraturas, alterações do sono, ansiedade e depressão. ${ }^{9}$ Nestes pacientes, é comum a constatação da síndrome do imobilismo, para o qual se indicou, associados à fisioterapia, hidroterapia e acompanhamento psicológico.

Foi descrita a evolução de caso de TCG do sacro de difícil controle em adulto jovem, inoperável, onde foi realizada a embolização, uso de interferon e radioterapia, associados ao uso de opioides e de medicamentos coadjuvantes, acompanhamento psicológico e fisioterápico, revelando o difícil controle da dor. Conseguiu-se a estabilização do crescimento tumoral e da dor após vários procedimentos e 9 anos de seguimento.
Conflitos de Interesses

Os autores declaram não haver conflitos de interesses.

\section{Referências}

1 Camargo OP, Croci AT, Oliveira CR, Baptista AM, Caiero MT, Giannotti MA. Tumor de células gigantes: evolução histórica do seu diagnóstico e tratamento junto ao Instituto de Ortopedia e Traumatologia da FMUSP. Acta Ortop Bras 2001;9(04): 46-52

2 Catalan J, Fonte AC, Lusa JRB, Oliveira AD, Melo ES, Justino Júnior RO, et al. Tumor de células gigantes ósseo: aspectos clínicos e radiográficos de 115 casos. Radiol Bras, São Paulo 2006;39(02):119-122

3 Ciftdemir M, Kaya M, Selcuk E, Yalniz E. Tumors of the spine. World J Orthop 2016;7(02):109-116

4 King T, Porreca F. Opioids in cancer pain: new considerations. Pain Clin Updates IASP. 2010;18(01):1-5

5 Yasko AW. Interferon therapy for giant cell tumor of bone. Curr Opin Orthop 2006;17:568-572

6 Formenti SC, Demaria S. Systemic effects of local radiotherapy. Lancet Oncol 2009;10(07):718-726

7 Branstetter DG, Nelson SD, Manivel JC, Blay JY, Chawla S, Thomas $\mathrm{DM}$, et al. Denosumab induces tumor reduction and bone formation in patients with giant-cell tumor of bone. Clin Cancer Res 2012;18(16):4415-4424

8 Ferreira KAS, Kimura M, Teixeira MJ, Nobrega JC. Preditores de controle inadequado da dor entre pacientes com dor oncológica. In: $7^{\circ}$ Congresso Brasileiro de Dor, Gramado, RS; 2006

9 Junming M, Cheng Y, Dong C, Jianru X, Xinghai Y, Quan H, et al. Giant cell tumor of the cervical spine: a series of 22 cases and outcomes. Spine 2008;33(03):280-288 